\title{
The Australasian Hepatology Association consensus guidelines for the provision of adherence support to patients with hepatitis C on direct acting antivirals
}

\author{
This article was published in the following Dove Press journal: \\ Patient Preference and Adherence \\ 13 December 2016 \\ Number of times this article has been viewed
}

\author{
Jacqueline A Richmond ${ }^{1,2}$ \\ Suzanne Sheppard-Law ${ }^{3,4}$ \\ Susan Mason ${ }^{5}$ \\ Sherryne L Warner ${ }^{6,7}$ \\ 'Australian Research Centre in \\ Sex, Health and Society, La Trobe \\ University, ${ }^{2}$ Victorian Infectious \\ Diseases Service, The Royal \\ Melbourne Hospital, Melbourne, \\ VIC, ${ }^{3}$ Faculty of Health, University \\ of Technology, ${ }^{4}$ Sydney Children's \\ Hospital Network, ${ }^{5} \mathrm{AW}$ Morrow \\ Gastroenterology and Liver Centre, \\ Royal Prince Alfred Hospital, \\ Sydney, NSW, ${ }^{6}$ Department of \\ Gastroenterology, Monash Health, \\ ${ }^{7}$ Department of Medicine, Monash \\ University, Melbourne, VIC, Australia
}

Correspondence: Jacqueline A Richmond Viral Hepatitis Research Program, Australian Research Centre in Sex, Health and Society, La Trobe University, 2I 5 Franklin Street, Melbourne, VIC 3000 , Australia

$\mathrm{Tel}+6$ I 488662268

Email j.richmond@latrobe.edu.au
Background: Hepatitis C is a blood-borne virus primarily spread through sharing of drug-injecting equipment. Approximately 150 million people worldwide and 230,000 Australians are living with chronic hepatitis C infection. In March 2016, the Australian government began subsidizing direct acting antivirals (DAAs) for the treatment of hepatitis C, which are highly effective ( $95 \%$ cure rate) and have few side effects. However, there is limited evidence to inform the provision of adherence support to people with hepatitis $\mathrm{C}$ on DAAs including the level of medication adherence required to achieve a cure.

Methodology: In February 2016, a steering committee comprising four authors convened an expert panel consisting of six hepatology nurses, a hepatologist, a pharmacist, a consumer with hepatitis $\mathrm{C}$ and treatment experience, and a consumer advocate. The expert panel focused on the following criteria: barriers and enablers to DAA adherence; assessment and monitoring of DAA adherence; components of a patient-centered approach to DAA adherence; patients that may require additional adherence support; and interventions to support DAA adherence. The resultant guidelines underwent three rounds of consultation with the expert panel, Australasian Hepatology Association (AHA) members ( $n=12$ ), and key stakeholders $(n=7)$ in June 2016. Feedback was considered by the steering committee and incorporated if consensus was achieved.

Results: Twenty-four guidelines emerged from the evidence synthesis and expert panel discussion. The guidelines focus on the pretreatment assessment and education, assessment of treatment readiness, and monitoring of medication adherence. The guidelines are embedded in a patient-centered approach which highlights that all patients are at risk of nonadherence. The guidelines recommend implementing interventions focused on identifying patients' memory triggers and hooks; use of nonconfrontational and nonjudgmental language by health professionals; and objectively monitoring adherence.

Conclusion: These are the first guidelines to support patients and health professionals in the delivery of clinical care by identifying practical adherence support interventions for patients taking DAAs.

Keywords: nursing, adherence, best practice, nursing support, hepatitis $\mathrm{C}$ treatment

\section{Introduction}

Infection with hepatitis $\mathrm{C}$ virus and the resultant liver disease is a global public health issue affecting approximately 150 million people worldwide and an estimated 230,470 Australians. ${ }^{1}$ Australia is in the unique position, globally, to have diagnosed approximately $75 \%$ of people affected by hepatitis $C$; however, treatment rates remain 
low by global standards with only $26 \%$ having received treatment and the proportion of people being treated each year remaining unchanged, at $1 \%$, since $2007 .^{2}$

On March 1, 2016, Australia became one of the few developed countries to publicly subsidise curative direct acting antivirals (DAAs) regimens for all people with hepatitis $\mathrm{C}$ infection. The Australian health care system is operated by both government and private institutions. The universal health care system, Medicare, is administered by the Australian Federal Government and coexists with a private health system. The federal government also funds the Pharmaceutical Benefits Scheme (PBS) which subsidises a range of prescription medications. The listing of the DAAs on the PBS ensures that anyone diagnosed with hepatitis $\mathrm{C}$ regardless of their stage of liver disease can access DAAs. Due to their high cost and the potential (low) risk of developing viral resistance after unsuccessful cure, the Australasian Hepatology Association (AHA) strongly advocates that every effort be made to ensure that all patients commenced on a DAA regimen be given the optimal chance of cure on their first attempt. High adherence is a process, not an isolated event, and it is critical that adherence support is integrated into the practice of all members of the interdisciplinary team.

Experience gained from the treatment of chronic infectious diseases such as the human immunodeficiency virus (HIV) and tuberculosis has shown that even the most motivated patient is susceptible to waning medication adherence. ${ }^{3}$ Medication adherence is a complex multidimensional phenomenon influenced by numerous factors. The World Health Organisation (WHO) suggests that adherence is influenced by a complex interaction of five domains: social and economic system, health care system, disease-related factors, treatmentrelated factors, and individual factors. ${ }^{3}$ Multiple strategies and/or interventions are necessary to address adherence to DAA regimens by people with hepatitis $\mathrm{C}$ infection.

There is limited evidence to assist the interdisciplinary team, including nurses, general practitioners (GPs), medical specialists, and community and peer workers, to provide adherence support to people with hepatitis C taking DAAs. The purpose of this article is to synthesize evidence and expert opinion on the provision of adherence support through discussion with an expert panel. The outcome is a series of consensus guidelines for implementation in the hepatitis $\mathrm{C}$ clinical setting (Box 1).

A Consensus Statement $2016^{4}$ outlines the clinical management of hepatitis C DAA treatment. The AHA Consensus Guidelines on the Provision of Adherence Support for People with Hepatitis C on DAAs (2016) support the clinical recommendations made in the consensus statement. ${ }^{4}$ The two
Box I Consensus guidelines

I. Optimal adherence to the hepatitis C DAAs is yet to be determined. Therefore, it is recommended that every effort is made to support patients to be $100 \%$ adherent to DAAs.

2. The patient-centered approach underpins the delivery of DAA adherence support.

3. All patients are at risk of nonadherence (intentional and/or unintentional).

4. Patients benefit from receiving holistic care from members of the interdisciplinary team.

5. All patients should have the opportunity to engage in a pretreatment assessment with a health professional knowledgeable about hepatitis $C$.

6. All patients should have the opportunity to discuss their readiness to commence DAA treatment with a health professional knowledgeable about hepatitis $C$.

7. The decision to commence DAA treatment is shared between the patient with hepatitis $C$ and their treating clinician.

8. Where possible, people with hepatitis $C$ should have the opportunity to choose the clinical setting where they access DAA treatment (excluding patients with complex comorbidities, such as, but not limited, to cirrhosis).

9. Pretreatment education should adopt a patient-centered approach incorporating the patient's health literacy and cultural needs.

10. Using a patient-centered approach pretreatment education should include a discussion about harm minimization strategies to reduce the risk of reinfection.

II. The "teach-back" method could be used to confirm that the patient has understood the information provided during the education session.

12. Health professionals and patients should identify possible factors that may impact on adherence prior to the patient commencing treatment.

13. Health professionals should support patients to select and implement an individualized adherence support strategy (incorporating memory triggers and hooks).

14. A patient-centered approach should be used to assess and implement adherence support interventions.

15. When exploring nonadherence with patients, health professionals should use nonconfrontational and nonjudgmental language.

16. Using "normalization" and "gentle assumption" interviewing techniques can improve the validity of patient responses when exploring nonadherence.

17. Health professionals should adopt a shared decision-making approach with the patient when devising the care plan including the most appropriate education and adherence support strategies.

18. Tools to assess and support medication adherence include visual analogue scales, pharmacy data, pill counts, and DOT.

19. Patients who would like to access their DAA treatment through a community pharmacy should communicate with their preferred pharmacists about their capacity to supply the medication.

20. Patients should be encouraged to communicate with their preferred pharmacists about how much time is required to order a repeat prescription.

2I. The patient should be encouraged to document the first day they start taking DAA treatment to ensure that on-treatment and offtreatment monitoring is scheduled appropriately.

22. Medication adherence may be supported by feedback from pathology results, although this has not been validated as an adherence assessment tool. 


\section{Box I (Continued)}

23. Health professionals should ensure that patients have contact details for professional DAA treatment support including their general practitioner.

24. The patient's end-of-treatment outcome and self-reported level of adherence should be documented in the medical history.

Abbreviations: DAA, direct acting antiviral; DOT, directly observed treatment.

documents are intended to be used in conjunction to promote patient adherence to DAAs.

\section{Methodology}

In February 2016, a steering committee comprising four authors convened an expert panel on behalf of the AHA. The expert panel consisted of six hepatology nurses, a hepatologist, a GP with experience on hepatitis $\mathrm{C}$ treatment, a tertiary hospital-based pharmacist, an individual with personal experience on hepatitis $\mathrm{C}$ and DAA treatment, and a representative of Hepatitis Australia. An evidence-based briefing document providing an overview of hepatitis $\mathrm{C}$ and adherence support was circulated to the expert panel 1 week prior to the meeting. The meeting sought to achieve consensus through group discussion on the following questions:

- What are the facilitators and barriers of adherence to DAAs in patients with hepatitis C?

- How is adherence in the DAA era defined?

- What is the acceptable minimum number of tablets that should be taken?

- How can hepatology nurses assess adherence to DAAs actual and projected adherence?

- How can we monitor adherence to DAAs?

- What are the key components of a patient-centered approach to DAA adherence?

- Are there patients who require additional adherence support?

- Priority and special populations?

- Which groups may need additional adherence support?

- How can hepatology nurses support adherence to DAA regimens (eg, interventions)?

The discussion was audio recorded and transcribed by a consultant medical writer. Familiarization of the transcript content was undertaken by the steering committee. Key concepts were identified and a preliminary draft document was prepared by the first author. The draft document was circulated to the expert panel, AHA member volunteers $(n=12)$, and key stakeholders $(n=7)$ in three consultation phases. Each consultation phase was iterative and involved collecting feedback on the updated document and responses to an online survey. Feedback was considered by the steering committee and incorporated if consensus agreement was achieved. Where disagreement about the inclusion or wording of a guideline occurred, the steering committee made the final decision after in-depth discussion. The resulting consensus is presented.

\section{Medication adherence in a chronic disease setting}

A chronic disease is defined as an illness lasting longer than 6 months. Medications that are prescribed to treat chronic disease aim to cure, optimize health, and/or prevent further health deterioration; however, treatment outcomes are only achieved if patients adhere to the medication regimen. Conversely, poor medication adherence reduces the potential for cure, increases the cost to public health, and reduces an individual's productivity. ${ }^{5-9}$ Rates of medication adherence in chronic disease settings are well described in the literature. Adherencebased studies in cardiovascular disease, diabetes, bipolar disorder, chronic obstructive airways disease, tuberculosis, and HIV report adherence rates between $30 \%$ and $92 \% .{ }^{10-14}$ The significant variation in reported medication adherence rates are related to methodological issues, specifically lack of consistency in defining and measuring adherence. ${ }^{15}$

The AHA has adopted the WHO definition of adherence:

The extent to which a person's behaviour - taking medication, following a diet, and/or executing lifestyle changes corresponds with agreed recommendations from a health care provider. $^{3}$

Medication adherence relates to the way an individual takes a prescribed medication, including the use of the correct medication, the correct dose and time, duration and timely refill of a repeat prescription. "Adherence" implies that a patient is actively engaged in the decision-making process and has agreed to take the medication, whereas "compliance" suggests that a patient is a passive recipient of health care. ${ }^{3}$ The AHA is promoting a patient-centered approach to the delivery of adherence support; therefore, "adherence" is the preferred term and is used throughout this document.

Nonadherence can be either intentional or unintentional. Intentional nonadherence refers to ceasing medication for prolonged periods of time and complete cessation without medical consultation or advice. In contrast, unintentionalnonadherence refers to accidentally missing doses and/or not understanding the dosing as it was prescribed. ${ }^{16}$

\section{Optimal adherence for hepatitis C DAA treatment}

Research exploring adherence in the "real world" of hepatitis C DAAs is limited, and the level of adherence 
required to achieve a sustained virological response (SVR) or cure remains unclear. Phase III trials that evaluated the effect of ledipasvir (LDV) and sofosbuvir (SOF) in 1900 treatment-naïve and treatment-experienced patients with genotype 1 showed two cases of virological breakthrough on treatment. Both patients were suspected of nonadherence. ${ }^{17,18}$ A further study of LDV/SOF with or without ribavirin (RBV) in patients with genotype 1 and cirrhosis, who were nonresponsive to previous protease inhibitor therapy, recorded medication adherence as either $<80 \%$ or $>80 \%$. In the LDV/SOF and RBV group, four patients had $<80 \%$ adherence; however, they all achieved an SVR (negative for hepatitis $\mathrm{C}$ virus 12 weeks posttreatment). ${ }^{19}$ Adherence was further evaluated in patients with hepatitis $\mathrm{C}$ mono-infection $(n=20)$ and patients with HIV/hepatitis C coinfection $(n=50)$. Tablets were counted which revealed that $40 \%$ of patients had missed one to four doses, $3 \%$ had missed five to eight doses, and 7\% missed more than eight doses. Ninety-nine percent of patients $(n=69)$ achieved an SVR. ${ }^{19}$

Further research suggests that while adherence to DAA regimens is high overall, it diminishes with longer treatment courses, particularly between weeks 8 and 12, among people with hepatitis $\mathrm{C}$ genotype 1 and people coinfected with hepatitis $\mathrm{C}$ and HIV. ${ }^{20,21}$ Older patients with a high number of comorbidities are also more likely to be nonadherent. ${ }^{22}$ Missed doses and double dosing are the most commonly reported forms of nonadherence. ${ }^{23}$ Therefore, regularly assessing medication adherence is worthwhile.

Although DAAs are more potent, the risk of developing genotypic resistance exists. ${ }^{24}$ The role of resistant-associated substitutions (RAS) in DAA regimens is an active field of research. Baseline RAS are present in all patients with hepatitis $\mathrm{C}$ naïve to treatment. NS5A-treatment-emergentRAS in treatment-experienced patients can persist and create difficult retreatment challenges. The role of adherence in the development of RAS has not been directly studied but is likely to be a significant contributor. ${ }^{25}$

To realize the World Health Assembly's goal of eliminating hepatitis $\mathrm{C}$ by $2030,{ }^{26}$ people with preexisting drug and alcohol and/or mental health issues, people in custodial settings, and Aboriginal and Torres Strait Islander people, who have previously had hepatitis $C$ treatment deferred due to potential side effects and concerns about nonadherence, can be prioritized for DAA treatment. ${ }^{27}$ There is extensive evidence to support the treatment and management of patients with hepatitis $\mathrm{C}$ who currently inject drugs in interdisciplinary, community-based settings and further evidence that adherence and response rates to interferon (IFN)-based treatment is similar to nondrug using populations. ${ }^{28-34}$ There is little evidence to support withholding hepatitis $C$ treatment from people who inject drugs because of the potential for reinfection, as rates of reinfection following SVR are reportedly low at $<5 \%$ per year even with the use of IFN-based treatments. ${ }^{35}$ Intensive case management can be particularly helpful to ensure that people who inject drugs remain in care and are adherent to medication regimens; some will require assistance with housing and treatment for comorbidities including psychiatric and substance use issues. ${ }^{24}$

\section{Patient-centered approach}

The AHA promotes a patient-centered approach to the delivery of hepatitis C DAA treatment. A patient-centered approach involves health professionals responding respectfully to every patient within their care, treating them as an individual, rather than as an illness or condition requiring management. ${ }^{36}$ This approach promotes the patient as an active partner with the health professional in their care. The care is focused on the individual's personal health needs, wants, desires, and goals. Patient-centered care is a fundamental nursing concept, which underpins all nursing practice. The principle of patient-centered care guides the interpretation of the AHA's consensus-based nursing guidelines ${ }^{37}$ and Practice Standards ${ }^{38}$ and is acknowledged in the Australian nursing codes, guidelines, decision-making frameworks, and standards for practice that guide nursing care. ${ }^{39}$

A patient-centered approach establishes the foundation to provide adherence support to people with hepatitis $\mathrm{C}$ on DAAs. An in-depth understanding of individualized adherence-related issues enables clinicians to ask appropriate questions to discuss adherence-enhancing strategies with their patients. ${ }^{40}$ The pretreatment nursing assessment and the provision of on-treatment adherence support and monitoring must be individualized to overcome barriers and address the needs of the individual seeking care.

\section{Interdisciplinary approach}

Worldwide, the team of health professionals caring for patients with hepatitis $\mathrm{C}$ is expanding to include hepatology nurses, nurse practitioners, nurses working in primary care, gastroenterologists, hepatologists and infectious diseases physicians, GPs and other medical practitioners (including sexual health, and drug and alcohol physicians), social workers and psychologists, pharmacists, and peer workers. The expansion is likely to yield benefits in terms of patient education and support and the provision of adherence support. Consistent with the AHA's consensus-based nursing 
guidelines,${ }^{37}$ the term interdisciplinary team incorporates different disciplines into a single assessment of, and consultation with, the patient. This approach promotes patient-centered care because the patient is involved in discussions and decisions regarding their care and management. Interdisciplinary teams facilitate greater collaboration between health professionals and disciplines and theoretically deliver optimal patient outcomes. ${ }^{41}$

\section{Assessing and supporting patient adherence with DAAs}

Monitoring patient adherence and identifying individuals who need additional support is important in the DAA treatment era. Such practice will ensure that the "real-world" data reflect the high cure rates achieved in clinical trials. ${ }^{42}$

There have been several qualitative studies exploring factors that influence patient adherence in the setting of pegylated IFN (PEG-IFN), RBV, and once-daily DAAs. ${ }^{40}$ Fear of hepatitis C-related morbidity and mortality and understanding that treatment could be curative were significant motivators for both uptake and completion of treatment. ${ }^{40,43}$ Obtaining information during treatment on the likelihood of treatment success through viral load testing was identified in one study as an adherence motivator. ${ }^{44}$ While experience of hepatitis C-related stigma, often related to a history of injecting drug use, was also associated with medication adherence. ${ }^{42,45}$ Sublette et $\mathrm{al}^{42}$ found that participants reported feeling "unclean" and "embarrassed about divulging their status to doctors and dentists", but this stigma disappeared once they had been cured of hepatitis C. ${ }^{42}$ The pervasive and negative impact of hepatitis $\mathrm{C}$-related stigma on treatment adherence has highlighted the importance of the patient-health professional relationship, in terms of ameliorating the effects of stigma and building trust, which can improve adherence to care. ${ }^{46}$

Commitment of patients to nurse or clinician who treats hepatitis $\mathrm{C}$ virus infection is regularly identified as a strong facilitator of medication adherence, particularly in the setting of a collaborative relationship and open communication, which lead to honest dialogue about challenges to adherence. ${ }^{40,42}$ In addition, social and emotional support provided by family and friends is critical to facilitating medication adherence, particularly in the setting of adverse treatment side effects. External support develops individuals' self-efficacy and confidence to successfully engage in goal-directed behavior, and it has been shown to influence medication adherence across many chronic illnesses. ${ }^{47}$

People have devised ways to organize their daily routine to incorporate medication dosing into their lives in a "ritualistic" manner. However, changes in the daily routine such as being busy or traveling away from home can challenge adherence. Many routines focus on pairing administration of oral medications with meal times, and other personally important "hooks". Other participants described a heightened sense of anxiety that drove their adherence to the treatment. ${ }^{23}$

While there is an expectation of improved adherence to the simplified DAA regimens, DAAs are now being prescribed to patients who would not have previously been offered PEGIFN-based regimens, with reduced monitoring and interaction with health professionals. ${ }^{42}$ Patient-related factors including forgetfulness, busy daily schedules and responsibility to family and friends, mental health issues, stigma, and low heath literacy will remain significant considerations when assessing the likelihood of patient adherence. ${ }^{48,49}$ Assessing and supporting patient adherence needs to be incorporated into clinical care by all health professionals involved in the treatment of people with hepatitis $\mathrm{C}$ infection.

\section{Pretreatment assessment}

In the era of DAA treatment, encounters with patients will be significantly reduced once on treatment; therefore, the pretreatment assessment is a critical time to discuss medication adherence and develop or identify strategies that could be used to support adherence. Optimizing the chance of cure requires a high level of adherence to the DAA regimens and completing the full course of treatment.

Establishing a productive and supportive clinical rapport is vital to support the patient's medication adherence. The pretreatment assessment could occur on the day the patient starts the treatment or weeks beforehand depending on how prepared the patient is to commence DAA treatment and how thoroughly they have been assessed, including assessment of liver diseases. The clinical pretreatment assessment involves exploring the patient's medical and medication history, physical examination, virology investigations, and other investigations, including pathology and fibrosis assessment. ${ }^{4}$ In addition, the pretreatment assessment should include exploration of the patient:

- Treatment readiness

- Pretreatment educational needs

- Lifestyle particularly focused on facilitators and barriers to medication adherence.

\section{Treatment readiness}

The best time to start DAA treatment is when the patient is ready. It is more likely that DAA treatment will fail in patients 
who are not prepared for treatment as a consequence of low motivation. A patient's readiness to start treatment should be assessed prior to commencing, by a nurse, medical practitioner, peer worker, and/or community worker. Adopting a patient-centered approach will mean the structure of a treatment readiness assessment will vary but fundamentally it should explore the patient:

- Educational needs about hepatitis C, disease progression, and DAA treatment

- Understanding of their own clinical condition

- Beliefs about DAA treatment and the required level of adherence

- Lifestyle including potential facilitators and barriers to optimal adherence

- Preferences for where they access DAA treatment, for example, at their GP clinic or local community health center or tertiary hospital.

Individuals should be able to make an informed decision about when to start DAA treatment. The success of treatment is likely to be improved if the decision is shared between the patient and the treating clinician..$^{50}$

\section{Pretreatment education}

It is important in the initial discussion to explore the patient's level of hepatitis C knowledge and beliefs, and whether they have any concerns about DAA treatment. Pretreatment education should include consideration of the following topics:

- Hepatitis $\mathrm{C}$ disease and disease progression

- The need for DAA treatment

- How the DAAs work and possible side effects

- Relevant monitoring and surveillance testing during and after treatment completion

- Overview of medication adherence and importance of adherence to the DAAs

- Potential for drug-drug interactions, decreased efficacy of DAAs, and increased adverse effects due to prescribed and nonprescribed medications

- Strategies to support adherence

- Importance of discussing potential and actual adherence problems and the importance of completing the course of DAA treatment with a health professional and seeking adherence guidance promptly ${ }^{51}$

- Harm minimization strategies to prevent and reduce hepatitis $\mathrm{C}$ reinfection through injecting drug use, intranasal drug use, unsafe sexual practices, and cultural practices
- Disclosure and privacy issues related to hepatitis $\mathrm{C}$ and DAA administration; the impact of hepatitis C-related stigma and discrimination on DAA adherence. ${ }^{42}$

Underpinning the delivery of pretreatment education is the patient-centered approach. Individualizing the delivery of the education to the patient's level of health literacy, English (or preferred first language) proficiency, and cultural background will enhance its effectiveness. Health professionals may consider using the "teach-back" method to confirm whether a patient understands what is being explained to them by a health professional. ${ }^{52}$ If the patient understands, they are able to "teach-back" the information accurately. Verbal information should be reinforced with electronic or written information produced by local hepatitis organizations and/or pharmaceutical companies that the patient can take home.

\section{Lifestyle assessment}

Exploring an individual's day-to-day routine prior to commencing DAA treatment can assist the health professional and patient to identify potential facilitators and threats to medication adherence. Many people live unstructured lives, while others are well organized and regimented in their daily routines. However, everyone experiences unpredictable events that disrupt daily routines and, therefore, threaten medication adherence.

A central goal of the pretreatment assessment is to explore the patient's lifestyle to assist them to identify personally significant "hooks" or "triggers" that could be used to pair with the administration of medication. Asking the patient about the first thing they do when they wake up and/or the last thing they do before going to bed might be a useful way to start the conversation. Health professionals and patients should consider the following aspects of the patient's life in terms of facilitating or threatening medication adherence: ${ }^{51}$

- Accommodation - stable or unstable housing?

- Employment - shift work, work-related travel?

- Financial - difficulty paying the dispensing fee at the pharmacy, or for the GP consultation?

- Drug and alcohol use - potential for disruption of daily routines and impact on medication adherence. ${ }^{53}$

- Hepatitis C-related stigma and discrimination - impact on the patient's ability to use adherence support strategies such as lifestyle routine, due to fear of disclosure of hepatitis $\mathrm{C}$ status.

- Prescribed and/or nonprescribed medications including herbal preparations and vitamins should be assessed during every clinical encounter. 
- Depression - needs to be addressed prior to commencing DAA treatment. ${ }^{54}$

- Social life - weekday and weekend activities that may disrupt the daily routine?

- Cultural or health belief considerations that may impact on adherence.

- Eating habits - does the patient have regular eating, cooking, and shopping habits?

- Waking and sleeping habits.

Lifestyle assessment may require the inclusion of the patient's family and/or friends to help document the daily routine and contingency plans to support medication adherence.

\section{Interventions to support adherence}

Supporting an individual's DAA adherence encompasses interventions focused on the following:

- Patient

- Health professionals involved in the patient's care

- Tools to support patient adherence

- Health system.

\section{Patient adherence support interventions}

There are a range of interventions that could be used to support patient adherence to DAAs (Table 1). Each intervention needs to be considered in terms of a patient-centered approach; what works for one person may not work for another. Considering adherence interventions prior to commencing DAA treatment may assist patients to prioritize adherence and establish adherence-promoting routines.

While it might be useful for the patient to have a separate reserve supply of medication at their workplace, or friend's house or in the pocket of a bag, the expense of the hepatitis C DAAs precludes this backup system.

\section{Health professionals' role in promoting adherence support}

Research has consistently shown that health professionals' assessment of adherence to HIV medication is overestimated unless a validated assessment tool is used. ${ }^{55}$ Several studies have demonstrated the benefits of interdisciplinary care including nurses and pharmacists on patient adherence to hepatitis $\mathrm{C}$ treatment. ${ }^{56-58}$ While health professionals provide support which enables adherent behavior, they may inadvertently reinforce nonadherence by conveying displeasure when a patient discloses a missed dose(s).The concept of social desirability is well described in the adherence literature, whereby patients underreport medication
Table I Memory triggers and hooks to support medication adherence

Strategic position of medication near an object or behavior that the patient does ritually every day:

- Between the toothbrush and toothpaste

- Next to other medications or vitamins

- On the bed or pillow

- Next to or on top of the alarm clock in the bedroom

- Beside the kettle or coffee jar

Automated reminders:

- Setup a daily alarm on the patient's smartphone or device

- Download a reminder application for the patient's smartphone or device

- Reminder notes on the fridge

- Medication dosing diary

Medication dispensing devices:

- Dosette box

- Daily assisted dosing

- Directly observed treatment

Note: Data from references $5 \mathrm{I}$ and 60.

adherence to appease their clinicians. The use of nonconfrontational and nonjudgmental language provides an environment that is conducive to clinician-patient communication and allows for patient disclosure of nonadherent behavior and the reasons for missed medication. The way health professionals ask patients about missed doses plays a significant role in determining the validity of the answers provided. ${ }^{59}$ Two interviewing techniques referred to as "normalization" and "gentle assumption" have been shown to improve the validity of patient responses when exploring sensitive topics. The technique involves normalizing the process of missed medication to reduce the patient's shame and guilt, while also assuming that medications have been missed rather than asking directly. ${ }^{60}$ Table 2 outlines examples of normalizing and assumption strategies that could be used in patient interactions to support medication adherence.

Importantly, health professionals should routinely enquire about adherence to DAA regimens whenever they have contact with the patient; a structured approach ensures patients are accustomed to thinking about adherence. Providing reassurance that they are not the only person who has forgotten to take their medication may provide patients with permission to fully discuss any potential adherence problems. While encouraging patients to monitor and document their missed doses may also empower the individual to identify the threats to their medication adherence.

\section{Tools to assess on-treatment adherence}

There are several evidence-based behavioral interventions aimed at improving medication adherence. ${ }^{61}$ Strategies 
Table 2 Linguistic strategies to support medication adherence in people with hepatitis $C$

\section{Potentially problematic language Preferred language}

Have you been taking the medication It is very easy to forget to the way it was prescribed?

take medication and easy to forget that you have taken the medication. If you notice yourself doing that, can you write down if there was anything inconvenient about the timing of the dose?

Have you been taking the medication the way I told you to? Many people forget to take medication (normalization). In the weeks since we last met, how many doses do you think you may have missed? (gentle assumption) Other people have had difficulty taking their medication ... have you experienced any issues?

Are you taking the medication as directed on the bottle/packet?

Have you missed any doses?

Note: Data from Shea. ${ }^{60}$

including implementing culturally appropriate education individualized to the patient's level of health literacy, increasing social support, providing medication reminder tools, strengthening the patient-health care provider relationship, and offering directly observed treatment (DOT) have all been shown to be successful. ${ }^{55}$ A systematic review of patient adherence to IFN-based treatment for hepatitis C concluded that the highest adherence rates were reported in studies that used patient self-report strategies to measure adherence, whereas the lowest rates were reported in studies using pharmacy refill claims. ${ }^{62}$

The impact of DOT was explored in a randomized control trial (RCT) of 21 patients with hepatitis $\mathrm{C}$ receiving antiviral treatment, and methadone maintenance. The RCT demonstrated that patients who underwent DOT had greater success in achieving an SVR. ${ }^{63}$ DOT has a dual advantage of allowing assessment of adherence and an intervention that supports patients at risk of low adherence. ${ }^{64,65}$

Evidence-based strategies to assess medication adherence are also available and include the following:

- Structured self-reporting using visual analogue scales, although these measures tend to overestimate adherence.

- Pharmacy data that indicates the frequency of refilling prescriptions (indirect confirmation).

- Electronic monitoring that records the opening and closing of the medication container.
- Pill counts that are commonly used in clinical trials. ${ }^{55}$

There are also a number of validated adherence assessment tools that could be implemented in clinical practice including the Adherence Starts with Knowledge-12 (ASK-12), ${ }^{66}$ the Brief Adherence Rating Scale (BARS) ${ }^{67}$ and the eight-item Morisky Medication Adherence Scale. ${ }^{68}$ Each tool is accessible on the Internet and relatively easy to administer.

\section{Health system}

In 2016, the Australian Government funded universal access to the hepatitis C DAAs and introduced systemic changes to medication prescribing and dispensing to support this. DAAs can now be prescribed by a broad range of medical practitioners under the section 85 PBS general listing and dispensed at community pharmacies. However, there have been initial community-based pharmacy implementation issues that may lead to the risk of unintended nonadherence.

To avoid unintended nonadherence, patients need to be adequately informed and educated prior to, and during, treatment so they can manage any implementation issues associated with community dispensing. To mitigate any risk of nonadherence, nurses should discuss the potential for short delays in dispensing their medications and encourage them to plan ahead. It is also preferable for repeat prescriptions to be dispensed by the same pharmacist (community or tertiary hospital based). If the patient maintains good communications with the pharmacist throughout the treatment course, it will have the added benefit of providing an additional point of access to health care information relevant to their condition.

\section{Monitoring treatment adherence and outcome}

In order to ensure accurate monitoring of patients on treatment, health professionals need to determine the date the patient commenced the DAAs. The Australian Recommendations for the Management of Hepatitis $\mathrm{C}$ indicate that a liver function test at week 4 of treatment is a suitable monitoring strategy. ${ }^{4}$ Adopting a patient-centered approach means the health professionals need to understand their patient's on-treatment monitoring needs. Some patients may require additional motivation to remain adherent; hence, judicious use of viral load testing in certain circumstances may be warranted.

Health professionals must be aware that side effects to the DAAs have been reported. While the reported side effects tend to be few and mild, there is a potential for medication 
side effects to affect patient adherence. Health professionals should ensure that every patient is provided with their contact details and invited to initiate contact if they have any concerns about the medication (including concerns about drug-to-drug interactions with the DAAs or commencing new medications during the treatment course) or administration of the medication including missed or double doses.

Documenting the patient's treatment outcome and their self-reported level of adherence at SVR 12 (12 weeks after treatment completion) is recommended. In the event of an unsuccessful course of treatment, it is important to ensure the patient receives appropriate ongoing care and support. The end-of-treatment time point also provides the health professional with an opportunity to evaluate and/or reflect on the impact of their clinical practice on the patient's medication adherence.

\section{Conclusion}

The development of DAAs has revolutionized hepatitis $\mathrm{C}$ treatment and management. However, medications only work when people take them. The AHA Consensus Guidelines on the Provision of Adherence Support for People with Hepatitis C on DAAs were developed by an expert panel to guide health professionals in providing practical adherence support for patients with hepatitis C on DAAs. The document emphasizes that all patients are at risk of nonadherence and "treatment readiness" is a pivotal concept that influences subsequent adherent behavior.

The AHA Board intends to review this document biennially, in order to incorporate the emergence of evidence and clinical developments, and to reflect the evolution of hepatitis C DAAs. The procedure used to update the guidelines will depend on the resources available at the time. For further information about the AHA refer to: www. hepatologyassociation.com.au.

\section{Acknowledgments}

The authors would like to acknowledge the contribution of the expert panel in the development of the guidelines: Dr David Baker, Anton Coleman, Susanne Glasgow, Dianne How-Chow, Tracey Jones, Associate Professor John Lubel, Saroja Nazareth, Shirley Ng, Kerry Paterson, Jana Vander Jagt, and Pam Wood. The authors also acknowledge the support of the Australasian Hepatology Association Board and members for their support and the key stakeholders who participated in the consultation process. This project was supported by an unrestricted educational grant from Bristol Myers Squibb.

\section{Disclosure}

The authors report no conflicts of interest in this work.

\section{References}

1. The Kirby Institute. HIV, Viral Hepatitis and Sexually Transmissible Infections in Australia - Annual Surveillance Report 2015. Sydney, Australia: The Kirby Institute, University of New South Wales; 2015.

2. Iversen J, Wand H, Topp L, Kaldor J, Maher L. Reduction in hepatitis C virus incidence among injection drug users attending needle and syringe programs in Australia: a linkage study. Am J Public Health. 2013;103(8): $1436-1444$.

3. Sabate E. Adherence to Long-Term Therapies: Evidence for Action. Geneva: World Health Organization; 2003. Available from: http://www. who.int/chp/knowledge/publications/adherence_report/en. Accessed December 19, 2015.

4. Hepatitis C Virus Infection Consensus Statement Working Group. Australian Recommendations for the Management of Hepatitis C Virus Infection: A Consensus Statement 2016. Melbourne: Gastroenterological Society of Australia; 2016.

5. Krueger KP, Berger BA, Felkey B. Medication adherence and persistence: a comprehensive review. Adv Ther. 2005;22(4):313-356.

6. Osterberg L, Blaschke T. Adherence to medication. NEngl J Med. 2005; 353(5):487-497.

7. Brown MT, Bussell JK. Medication adherence: WHO cares? Mayo Clin Proc. 2011;86(4):304-314.

8. Perrillo RP, Marcellin P. Effect of newer oral antiviral agents on future treatment of chronic hepatitis B. Antivir Ther. 2010;15(1):13-22.

9. Lehane E, McCarthy G. An examination of the intentional and unintentional aspects of medication non-adherence in patients diagnosed with hypertension. J Clin Nurs. 2007;16(4):698-706.

10. Clatworthy J, Bowskill R, Rank T, Parham R, Horne R. Adherence to medication in bipolar disorder: a qualitative study exploring the role of patients' beliefs about the condition and its treatment. Bipolar Disord. 2007;9(6):656-664.

11. Katon W, Russo J, Lin EH, et al. Diabetes and poor disease control: is comorbid depression associated with poor medication adherence or lack of treatment intensification? Psychosom Med. 2009;71(9):965-972.

12. Jung E, Pickard AS, Salmon JW, Bartle B, Lee TA. Medication adherence and persistence in the last year of life in COPD patients. Respir Med. 2009;103(4):525-534.

13. Heisler M, Choi H, Rosen AB, et al. Hospitalizations and deaths among adults with cardiovascular disease who underuse medications because of cost: a longitudinal analysis. Med Care. 2010;48(2):87-94.

14. Laba TL, Lehnbom E, Brien JA, Jan S. Understanding if, how and why non-adherent decisions are made in an Australian community sample: a key to sustaining medication adherence in chronic disease? Res Social Adm Pharm. 2015;11(2):154-162.

15. World Health Organisation (WHO). Adherence to Long-Term TherapiesEvidence for Action. Geneva, Switzerland: WHO; 2003.

16. The Pharmacy Guild of Australia. National Trial to Test Strategies to Improve Medication Compliance in a Community Setting. Australia: Department of Health and Ageing, The Australian Government; 2008.

17. Afdhal N, Zeuzem S, Kwo P, et al; ION-1 Investigators. Ledipasvir and sofosbuvir for untreated HCV genotype 1 infection. N Engl J Med. 2014;370(20):1889-1898.

18. Afdhal N, Reddy KR, Nelson DR, et al; ION-2 Investigators. Ledipasvir and sofosbuvir for previously treated HCV genotype 1 infection. NEngl J Med. 2014;370(16):1483-1493.

19. Bourliere M, Bronowicki JP, de ledinghen V, et al. Ledipasvir-sofosbuvir with or without ribavirin to treat patients with $\mathrm{HCV}$ genotype 1 infection and cirrhosis non-responsive to previous protease-inhibitor therapy: a randomised, double-blind, phase 2 trial (SIRIUS). Lancet Infect Dis. 2015;15(4):397-404. 
20. Townsend K, Petersen T, Gordon LA, et al. Effect of HIV co-infection on adherence to a 12-week regimen of hepatitis $C$ virus treatment with ledipasvir and sofosbuvir. AIDS. 2016;30(2):261-266.

21. Petersen T, Townsend K, Gordon LA, et al. High adherence to all-oral directly acting antiviral hepatitis $\mathrm{C}$ treatment among an inner-city patient population in a phase 2a study. Hepatol Int. 2016;10(2):310-319.

22. Kamble PS, Walker DR, Marx S, et al. Adherence and discontinuation rates of sofosbuvir-based regimens: modelling real world experience in a large managed care organization. Hepatology. 2015;62(S1):iiA-vA, 2A-1378A.

23. Evon DM, Edwards A, Straub B, Hurt CB, Thirumurthy H, Wohl D. Adherence to all-oral $\mathrm{HCV}$ treatment in patients with substance and alcohol use disorders. Hepatology. 2015;62(S1):iiA-vA, 2A-1378A.

24. Meyer JP, Moghimi Y, Marcus R, Lim JK, Litwin AH, Altice FL. Evidence-based interventions to enhance assessment, treatment, and adherence in the chronic Hepatitis C care continuum. Int J Drug Policy. 2015;26(10):922-935.

25. Lontok E, Harrington $P$, Howe A, et al. Hepatitis $C$ virus drug resistanceassociated substitutions: state of the art summary. Hepatology. 2015; 62(5):1623-1632.

26. [No authors listed]. Hepatitis C: only a step away from elimination? Lancet. 2015;385(9973):1045.

27. Gidding HF, Law MG, Amin J, et al; ACHOS investigator team. Predictors of deferral of treatment for hepatitis C infection in Australian clinics. Med J Aust. 2011;194(8):398-402.

28. Grebely J, Alavi M, Micallef M, et al; ETHOS Study Group. Treatment for hepatitis $\mathrm{C}$ virus infection among people who inject drugs attending opioid substitution treatment and community health clinics: the ETHOS Study. Addiction. 2016;111(2):311-319.

29. Dore GJ, Hellard M, Matthews GV, et al; Australian Trial in Acute Hepatitis C Study Group. Effective treatment of injecting drug users with recently acquired hepatitis $\mathrm{C}$ virus infection. Gastroenterology. 2010;138(1):123-135.

30. Grebely J, Knight E, Genoway KA, et al. Optimizing assessment and treatment for hepatitis $\mathrm{C}$ virus infection in illicit drug users: a novel model incorporating multidisciplinary care and peer support. Eur $J$ Gastroenterol Hepatol. 2010;22(3):270-277.

31. Jack K, Willott S, Manners J, Varnam MA, Thomson BJ. Clinical trial: a primary-care-based model for the delivery of anti-viral treatment to injecting drug users infected with hepatitis C. Aliment Pharmacol Ther. 2009;29(1):38-45.

32. Wilkinson M, Crawford V, Tippet A, et al. Community-based treatment for chronic hepatitis $\mathrm{C}$ in drug users: high rates of compliance with treatment despite ongoing drug use. Aliment Pharmacol Ther. 2009;29(1):29-37.

33. Grebely J, Genoway K, Khara M, et al. Treatment uptake and outcomes among current and former injection drug users receiving directly observed treatment within a multidisciplinary group model for the treatment of hepatitis C virus infection. Int J Drug Policy. 2007;18(5):437-443.

34. Guadagnino V, Trotta MP, Montesano F, et al; Nocchiero Study Group. Effectiveness of a multi-disciplinary standardized management model in the treatment of chronic hepatitis $\mathrm{C}$ in drug addicts engaged in detoxification programmes. Addiction. 2007;102(3):423-431.

35. Barua S, Greenwald R, Grebely J, Dore GJ, Swan T, Taylor LE. Restrictions for Medicaid reimbursement of sofosbuvir for the treatment of hepatitis $\mathrm{C}$ virus infection in the United States. Ann Intern Med. 2015;163(3):215-223.

36. Australian Commission on Safety and Quality in Health Care (ACSQHC). Patient-centred care: improving quality and safety through partnerships with patients and consumers. Sydney: ACSQHC; 2011. Available from: www.safetyandquality.gov.au. Accessed March 22, 2016.

37. Australasian Hepatology Association (AHA). The AHA consensus-based nursing guidelines for the care of patients with hepatitis B, hepatitis C, advanced liver disease and hepatocellular carcinoma. Sydney: AHA; 2012. Available from: http://www.hepatologyassociation.com.au/about-us/ consensus-based-nursing-guidelines/. Accessed March 22, 2016.
38. Australasian Hepatology Association (AHA). The AHA practice standards for the hepatology nurse. Adelaide: AHA; 2015. Available from: http://www.hepatologyassociation.com.au/about-us/practicestandards/. Accessed March 22, 2016.

39. Nursing and Midwifery Board of Australia (NMBA). Registered nurse standards for practice. Melbourne: NMBA; 2016. Available from: http:// www.nursingmidwiferyboard.gov.au. Accessed June 13, 2016.

40. Evon DM, Golin CE, Bonner JE, Grodensky C, Velloza J. Adherence during antiviral treatment regimens for chronic hepatitis $\mathrm{C}$ : a qualitative study of patient-reported facilitators and barriers. J Clin Gastroenterol. 2015;49(5):e41-e50.

41. Jessup RL. Interdisciplinary versus multidisciplinary care teams: do we understand the difference? Aust Health Rev. 2007;31(3): 330-331.

42. Sublette VA, Smith SK, George J, McCaffery K, Douglas MW. The hepatitis C treatment experience: Patients' perceptions of the facilitators of and barriers to uptake, adherence and completion. Psychol Health. 2015;30(8):987-1004.

43. Brett Hauber A, Mohamed AF, Beam C, Medjedovic J, Mauskopf J. Patient preferences and assessment of likely adherence to hepatitis $\mathrm{C}$ virus treatment. J Viral Hepat. 2011;18(9):619-627.

44. Fusfeld L, Aggarwal J, Dougher C, et al. Assessment of motivating factors associated with the initiation and completion of treatment for chronic hepatitis C virus (HEPATITIS C) infection. BMC Infect Dis. 2013;13:234.

45. Younossi Z, Henry L. Systematic review: patient-reported outcomes in chronic hepatitis $\mathrm{C}$ - the impact of liver disease and new treatment regimens. Aliment Pharmacol Ther. 2015;41(6):497-520.

46. Treloar C, Rance J, Backmund M. Understanding barriers to hepatitis C virus care and stigmatization from a social perspective. Clin Infect Dis. 2013;57(Suppl 2):S51-S55.

47. Bonner JE, Esserman D, Evon DM. Reliability and validity of a selfefficacy instrument for hepatitis $\mathrm{C}$ antiviral treatment regimens. $J$ Viral Hepat. 2012;19(5):316-326.

48. Rintamaki LS, Davis TC, Skripkauskas S, Bennett CL, Wolf MS. Social stigma concerns and HIV medication adherence. AIDS Patient Care STDS. 2006;20(5):359-368.

49. Wolf MS, Davis TC, Osborn CY, Skripkauskas S, Bennett CL, Makoul G. Literacy, self-efficacy, and HIV medication adherence. Patient Educ Couns. 2007;65(2):253-260.

50. Australian Commission on Safety and Quality in Health Care (ACSQHC). National safety and quality health service standards [September 2012]. Sydney: ACSQHC; 2012. Available from: www. safetyandquality.gov.au. Accessed March 23, 2016.

51. Adherence Project Working Group. Optimising Adherence to Antiretroviral Medication. Sydney: Adherence Project Working Group, Roche Products; 2001.

52. Agency for Healthcare Research and Quality (AHRQ). AHRQ Health Literacy Universal Precautions Toolkit. 2nd ed [content last reviewed November 2016]. Available from: http://www.ahrq.gov/literacy. Accessed March 23, 2016.

53. Hellard M, Sacks-Davis R, Gold J. Hepatitis C treatment for injecting drug users: a review of the available evidence. Clin Infect Dis. 2009; 49(4):561-573.

54. Mathes T, Antoine SL, Pieper D. Factors influencing adherence in hepatitis-C infected patients: a systematic review. BMC Infect Dis. 2014; $14: 203$.

55. Weiss JJ, Bräu N, Stivala A, Swan T, Fishbein D. Review article: adherence to medication for chronic hepatitis $\mathrm{C}$ - building on the model of human immunodeficiency virus antiretroviral adherence research. Aliment Pharmacol Ther. 2009;30(1):14-27.

56. Henderson RR, Visaria J, Bridges GG, Dorholt M, Levin RJ, Frazee SG. Impact of specialty pharmacy on telaprevir-containing 3-drug hepatitis C regimen persistence. J Manag Care Spec Pharm. 2014;20(12): 1227-1234. 
57. Rodis JL, Kibbe P. Evaluation of medication adherence and quality of life in patients with hepatitis $\mathrm{C}$ virus receiving combination treatment. Gastroenterol Nurs. 2010;33(5):368-373.

58. Namba S, Miyake K, Ikeda F, et al. Nursing support increases the efficacy of interferon treatment in patients with chronic hepatitis C. Acta Med Okayama. 2014;68(5):263-268.

59. Steel DJ, Jackson TC, Gutmann MC. Have you been taking your pills? The adherence-monitoring sequence in the medical interview. J Fam Pract. 1990;30(3):294-299.

60. Shea SC. Improving Medication Adherence - How to Talk with Patients About Their Medications. Philadelphia, PA: Wolters Kluwer Health Inc; 2006.

61. Simoni JM, Amico KR, Pearson CR, Malow R. Strategies for promoting adherence to antiretroviral treatment: a review of the literature. Curr Infect Dis Rep. 2008;10(6):515-521.

62. Lieveld FI, van Vlerken LG, Siersema PD, van Erpecum KJ. Patient adherence to antiviral treatment for chronic hepatitis $\mathrm{B}$ and $\mathrm{C}$ : a systematic review. Ann Hepatol. 2013;12(3):380-391.

63. Bruce RD, Eiserman J, Acosta A, Gote C, Lim JK, Altice FL. Developing a modified directly observed treatment intervention for hepatitis $\mathrm{C}$ treatment in a methadone maintenance program: implications for program replication. Am J Drug Alcohol Abuse. 2012;38(3):206-212.
64. Taylor LE. Delivering care to injection drug users coinfected with HIV and hepatitis C virus. Clin Infect Dis. 2005;40(Suppl 5):S355-S361.

65. Grebely J, Raffa JD, Meagher C, et al. Directly observed treatment for the treatment of hepatitis $\mathrm{C}$ virus infection in current and former injection drug users. J Gastroenterol Hepatol. 2007;22(9):1519-1525.

66. Matza LS, Park J, Coyne KS, Skinner EP, Malley KG, Wolever RQ Derivation and validation of the ASK-12 adherence barrier survey. Ann Pharmacother. 2009;43(10):1621-1630.

67. Byerly MJ, Nakonezny PA, Rush AJ. The Brief Adherence Rating Scale (BARS) validated against electronic monitoring in assessing the antipsychotic medication adherence of outpatients with schizophrenia and schizoaffective disorder. Schizophr Res. 2008;100(1-3):60-69.

68. Morisky DE, Ang A, Krousel-Wood M, Ward HJ. Predictive validity of a medication adherence measure in an outpatient setting. J Clin Hypertens (Greenwich). 2008;10(5):348-354.
Patient Preference and Adherence

\section{Publish your work in this journal}

Patient Preference and Adherence is an international, peer-reviewed, open access journal that focuses on the growing importance of patient preference and adherence throughout the therapeutic continuum. Patient satisfaction, acceptability, quality of life, compliance, persistence and their role in developing new therapeutic modalities and compounds to optimize

\section{Dovepress}

clinical outcomes for existing disease states are major areas of interest for the journal. This journal has been accepted for indexing on PubMed Central. The manuscript management system is completely online and includes a very quick and fair peer-review system, which is all easy to use. Visit http://www. dovepress.com/testimonials.php to read real quotes from published authors. 